\section{LAND UTILIZATION IN ENGLAND AND WALES}

$\mathrm{T}$ HE report which the Committee on Land Utilisa. tion in Rural Areas, under Lord Justice Scott as chairman, has submitted includes the majority report and also a minority report by Prof. S. R. Dennison, which differs in outlook and its observa. tions on policy rather than in the detail of the actual recommendations, particularly in regard to machinery and procedure, a note of reservation by Prof. Dennison and Mrs. H. Hichens and an additional memorandum on valuation and rating by the chairman, vicechairman, Mr. H. S. Cooper, Mr. A. E. Monks and Mr. P. Robinson. The Committee was appointed by Lord Reith in October 1941 to consider the conditions which should govern building and other constructional development in country areas of Great Britain consistently with the maintenance of agriculture, and in particular the factors affecting the location of industry, having regard to economic operation, part-time and seasonal employment, the well-being of rural communities and the preservation of rural amenities. The terms of reference did not include Scotland.

The majority report is in three parts. The first reviews the present position, successive chapters dealing with the land and population, the countryside, the impact of town on country, the effects of urban growth on the countryside, the War and probable post-war trends and planning powers. The admirable chapter on the countryside describes the pattern of the countryside and its evolution, including the influence of agriculture and types of farming and factors determining farming systems, the origins of the landscape pattern and the changes during the last few decades, as well as the drift from the land and its causes. The Committee points out that the beauty and patterm of the countryside are the direct result of the cultivation of the soil, and there is no antagonism between use and beauty. The physical impact of town on country is then analysed, as well as the consequences which have flowed from the greater appearance of the townsman in the country, whether as a rambler, a motorist or a week-end visitor. A study of the effects of urban growth on the countryside leads to the conclusion that, on balance, more harm than good has been done to the countryside in England and Wales by constructional development before the War, while the broad conclusions reached as a result of the review of the developments of the pre-war years and the changes brought about by the War are that the former trends of constructional development, with some slight modifications tending to a greater diffusion into country areas, will, unless checked and diverted, reassert themselves after the War. A post-war building boom, possibly even more intensive than that which took place in the 1920's, if left to take care of itself, will lead to the same and probably worse evils than those which characterized the inter-war period. The evils to the social wellbeing of town inhabitants as a result of ill-considered or uncontrolled urban spread are now well known, and the evils from the point of view of the country. side were no less apparent in the years leading up to the present War. The future of the countryside will be profoundly affected by the choice between haphazard and planned constructional development.

This argument for the immediate establishment of the necessary machinery for planning and control is reinforced by a survey of present planning powers, both of the Town and Country Planning Act, 1932, under which the unwillingness of many local authorities to collaborate with their neighbours has been lamentably apparent, and of the Restriction of Ribbon Development Act, 1935, the weaknesses of both Acts being concisely indicated. Both failed for the same reason-the claims for compensation against the authority administering the Act. Assuming therefore that the policy of the Government includes the establishment of a Central Planning Authority, the Committee in the third part of the report outlines the machinery and procedure required for planning and development. The Government machinery for the formulation and execution of national planning is conceived as consisting of a standing committee of the Ministers concerned under the chairmanship of a non-departmental Minister of Cabinet rank, Government departments concerned with development, a Central Planning Commission and such ad hoc bodies as may be required to carry out functions not already covered by existing Ministers or other authorities or bodies.

The Central Planning Commission should consist of a full-time independent paid chairman, with ministerial status, and a number of part-time or fulltime commissioners chosen on account of their special qualifications and knowledge as individuals of proved ability in their own spheres. The staff of the Commission should consist of Civil Service personnel, chosen with an internal knowledge of the departments with which the Commission will be in contact, and other persons, including some specialists, chosen for their knowledge of particular subjects and the prosecution of research. Outside London, the Commission should be represented by local officers to settle so far as possible all matters of local importance.

The duties of the Commission should include unified research and inquiry; the collection and correlation of information and the direction of research in connexion therewith; the formulation of national planning principles in accordance with directions received from the Minister, and the translation of national policy into concrete terms of national planning; the formulation and communication of general principles for the guidance of local planning authorities and the initiation, either direct or through the local officers, of schemes of national importance; and the approval or disapproval of plans submitted by local planning authorities and decisions thereon in accordance with Government policy. While much of the work of the Commission will be advisory, there should be a statutory obligation on all departmental Ministries to afford all requisite information to the Commission, and to consult with it and to consider its advice. Exceptionally, bodies with executive powers, for example, a National Parks Authority, may be set up where the policy of the Minister of National Planning requires executive action.

In regard to local planning, the report recommends that the local authorities continue to exercise their functions as planning authorities, but no longer without guidance, and it should not be possible for local authorities to refuse to co-operate in planning schemes. Local planning must be compulsory and not permissive. Normally, the primary local planning unit should be the county or a county borough and its surrounding area, or a comparable combination of local government units. Qualified personnel must be employed, and consultation between neighbouring planning authorities be compulsory. Local planning authorities should be freed from the restrictions in 
zoning agricultural land due to liability for compensation, and where they are carrying out their assigned part in a national plan, the expense should not fall on their own local financial resources.

In regard to procedure, the Committee considers that direct national action on broad lines will be required by the Central Planning Authority without waiting for the formulation and submission of planning schemes by local planning authorities. The work of determining the main types of land along the lines used by the Land Utilization Survey is part of the research which should be organized by or on behalf of the Central Planning Authority. The recommended procedure for controlling land use in country areas involves the national delineation of certain land areas; the local zoning of land similar to that adopted in present town and country planning schemes; and the consideration of individual cases in certain zones where such a course appears desirable.

In planning rural land, the majority report recommends that particular importance should be attached to agricultural considerations, and that land included in one of the categories of good land should not be alienated from its present use unless it can be clearly shown that it is in the national interest that the change should be made. Again, the majority report recommends that the power of compulsory acquisition of land by the State be exercised where required in the interests of national planning or for achieving that high degree of permanent efficiency in agriculture which vitally affects the essence of the problem. They recommend that the new $2 \frac{1}{3}$ in. to the mile maps be made available for all planning purposes, and stress the importance of adequate status and training of planners and architects. Great importance is attached to a very high standard of professional qualifications being required and maintained.

In the fourth part of the report, there is outlined a five-year plan for England and Wales, starting from the position as it will be after the War and not as it is at this moment, though between then and now the extremely important work of recording wartime changes and of collecting and tabulating statistically and cartographically the developments now taking place must be completed. Research work carried out by the Planning Division of the Ministry of Works and Planning, the Farm Survey of the Ministry of Agriculture, and the Nuffield College Social Reconstruction Survey are regarded as essential parts of the war effort. A proper co-ordination of the research underlying national planning is an essential function of the Central Planning Authority. While some of the essential research cannot be carried out until the War ends, the Committee recommends that a plan be drawn up, consistent with the general policy for continucus national planning, of work to be completed within five years.

Within the first year, the system of land classification for planning purposes should be agreed, and the standard procedure for co-operation between the appropriate town-planning oificers and officers representing agricultural and rural interests laid down, the panels of architects and planners set up, the comprehensive investigation of electricity, gas and water supplies and the demarcation of national parks and natural reserves completed, and the National Parks Authority established. The Government should lay down a definite agricultural and food policy for at least five years, having regard to the increasing knowledge of nutrition and the national health. Within the five years there should be completed first town- and country-planning schemes to cover the whole of England and Wales, providing a full indication of the areas where industrial zones are or are not to be established, and satellite towns or new settlements located; secondly, a definite number of houses for rural workers; a full survey of all villages and hamlets to determine the existing facilities for village social centres (including playing-fields), and the drawing up of a plan for the provision where suitable of centres of the village college type, and the opening in all counties of a long-term building programme; programmes for electricity, water and gas, based on the survey made in the first year; the national park scheme, with hostels, etc., in working order ; the determination and sign-posting of all footpaths and bridle-paths; rules, if any, for the control of access to the countryside, the use of commons and highways and other rights of way; the elimination of unsightly advertisements, petrol stations, etc. and the registration of title. With all this, an educational campaign to promote better understanding between town and country should be carried on continuously.

This outline of the recommended five-year plan indicates how comprehensive are the recommenda tions of the majority report detailed in Part II and summarized in Part V. Some of these have already been outlined in describing the five-year plan. Others relate to forestry and arboriculture, where an extension of afforestation on poor land together with the establishment of foresters' part-time holdings and national forest parks are recommended, as well as enforcement by the Forestry Commission of the proper management of all woodland in the country. In regard to village institutions, establishment of a permanent advisory committee on village life and institutions is recommended, as well as the provision of adequate playing-fields for every village. The importance attached to housing, to the provision of electricity at no higher price to the consumer than in the towns, the extension of gas supplies to rural areas, to a review of the whole question of water supply, all undertakings for which should be brought under national planning control, has already been indicated, while other major recommendations cover industry in country areas and housing and planning in such areas, as well as such matters as aerodromes, defence works, roads and railways, advertisements and cemeteries.

In regard to the farmer, it is recommended that extractive industries should be subject to effective planning control, and that in principle no person or body should be allowed to work land for the extraction of minerals and leave it in a derelict con. dition. Legislation should be passed imposing an obligation on all those who derive benefit from the working of land for minerals to restore that land for agriculture or afforestation or other purposes within a short specified time after the land has been worked out. The dispersal and future use of war factories established in the countryside should be determined by the Central Planning Authority in conjunction with the other departments concerned. Linked industries should remain in existing urban concen. trations or trading estates, and where light industries are brought into rural areas, they should be located in existing or new small towns. Production and storage units of public utility undertakings located in villages or in the open countryside should be subject to street planning control as regards siting and appearance. Rural trades and crafts should continue 
to be sited in small towns or villages and should be encouraged. No modern industry has been suggested which would provide seasonal or part-time employment for agricultural workers and their families, and appropriate bodies should be asked to make a special study of this problem. Before new towns are established in country areas, vacant or derelict industrial sites in existing towns should be fully utilized. New satellite towns, housing estates, garden cities and suburbs should be sited wherever practicable away from the better farm land, and due attention paid to agricultural considerations in their siting. Sporadie buildings in villages and rural areas should be controlled, and new villages and extensions of villages should be planned and should be so far as possible of a compact and closely knit character. All new villages and country towns should be situated away from main traffic roads though within easy access of them, and all existing villages and country towns which have main traffic roads running through them should be by-passed so far as possible. New buildings in country areas should use to the full all the possibilities which new materials and new building tech. niques have made available, though the buildings should be designed so as to harmonize with their surroundings.

\section{THEORY OF X-RAY DIFFRACTION}

\section{By Prof. P. P. EWALD}

Queen's University, Belfast

$\mathrm{T}$ $\mathrm{HE}$ numerous books on the diffraction of X-rays by crystals all treat the subject with the view of introducing the reader to the methods for determining erystal structures. It is true that some presentation of the theory of optical interference cannot be omitted and that the various books go into this theory to varying degrees. But it is only v. Laue's recent book* which makes the optical theory of X-ray interference in crystals its main aim. In it, the usual methods of crystal structure determination are curtailed or omitted, since they involve more geometrical than optical discussion, once the reduced intensities are taken as known. Omitted as well is the description of experimental methods, as the emphasis of the book is on theory.

What variety and scope the subject presents will become apparent on comparing it with the corresponding theory of the diffraction of light by a plane optical grating. This theory consists of two parts : the diffraction by a single element of the grating (slit, wire or groove) and the action produced by the repetition of such elements. The first part is not important for most aspects of the effect of a plane grating, other than the distribution of intensities over the spectra of different orders. Its counterpart in X-ray diffraction is the theory of the atomic factor, and this brings the subject at once into the domain of wavemechanical atomic theory.

The second part of the theory, the grating effect proper, is more involved for X-rays by the fact that they encounter in a crystal a three-dimensional grating. This fact leads to geometrical propositions concerning the main directions of diffraction which equal in beauty the geometrical constructions of the Fresnel-Hamiltonian crystal optics. Furthermore, the

* Röntgenstrahlinterferenzen. Von Prof. M. v. Laue. Pp. viii+358. (Leipzig : Akademische Verlagsgesellschaft Becker und Erler Kom.
Ges., 1941.) three-dimensionality of the crystal shape is carried over to the array of secondary diffraction maxima which surround each main maximum. The resulting complicated intensity distribution in space, modified by the 'erystal shape factor', is the three-dimensional generalization of the well-known one-dimensional diffraction function which determines the resolving power of a plane grating of finite width.

The most profound influence of the threedimensionality is, however, to be found in the strong interaction of each element with all its neighbours; this makes the theory of diffraction a part of the major problem of the propagation of an optical field through the erystal, that is, part of the problem of refraction and dispersion by the crystal. The resulting 'dynamical theory' of X-ray diffraction is fully treated in Laue's book.

While these points still bear a correspondence to the problems encountered for the plane grating, there are three others which have no counterpart. The first of these is due to the thermal motion of the diffracting centres, which not only produces an unavoidable irregularity of the lattice but also endows each centre with a velocity leading to a Doppler effect of the scattered radiation. The second new point is the production of scattered radiation of incoherent character and of Compton-modified frequency. The last is connected with the possibility of generating, for example by electronic bombardment of the crystal, monochromatic radiation at the interior of the crystal; this radiation has been shown by Kossel to emerge preferentially in certain directions.

The aspects of the theory as enumerated determine the scheme of Laue's book. The author starts with the theory of atomic scattering along wave-mechanical lines, but in rather a novel manner. He first points out that the general theory of integration of Maxwell's equations permits the introduction of various forms of scalar and vector potentials. Now for the perturbation problem of finding the scattered radiation without blurring the distinction between the perturbing incident potential and the normal constitutional potential of the atom, only one of these forms is suitable, namely that in which the fields derived from the vector potential cannot cancel those derived from the scalar potential. This is true for the atom as well as for the entire crystal, and the correct introduction of the potential is essential for the unity of method in treating atoms and crystals. The full development of the method will be found in the paragraphs introducing the dynamical theory, where the wave-mechanical concepts are further related to classical Maxwellian theory. The existence of the Schroedinger current can be interpreted classically as due to a changing polarization, and the polarization together with the electric field vector $E$ can be compounded to a dielectric displacement $D$ This is as in Lorentz's theory of electrons, except for the difference that $D$ is here a vector locally determined by the $\psi$-function for each electron, and not an average value over a distribution of polarization unknown in detail. The distinction between $E$ and $D$ leads to the definition of a dielectric constant which for a crystal is a periodic function in space. The theory of diffraction and of scattering is thus reduced to the problem of integrating the Maxwellian equations for the propagation of waves in a medium of varying dielectric constant. These variations are determined, according to wave-mechanics, by the ground state of the system as long as absorption is negligible, and by higher states as well near absorption edges. 